\title{
Adjunctive Application of Systemic Antibiotics in Non-surgical Aggressive Periodontitis Treatment: Clinical and Microbiological Findings
}

\author{
Iva Milinkovic ${ }^{1}$, Iva Mijailovic ${ }^{2}$, Aleksa Markovic $^{2}$, Bojan Janjic $^{2 *}$, Nadja Nikolic ${ }^{3}$, Jelena Milasin ${ }^{3}$, Biljana Milicic ${ }^{4}$, Zoran Aleksic $^{1}$, \\ Dina Vasovic ${ }^{5}$ \\ ${ }^{1}$ Department of Periodontology and Oral Medicine, School of Dental Medicine, University of Belgrade, Belgrade, Serbia; \\ ${ }^{2}$ Department of Oral Surgery, School of Dental Medicine, University of Belgrade, Belgrade, Serbia; ${ }^{3}$ Department of Human \\ Genetics, School of Dental Medicine, University of Belgrade, Belgrade, Serbia; ${ }^{4}$ Department of Statistics, School of Dental \\ Medicine, University of Belgrade, Belgrade, Serbia; ${ }^{5}$ Department of Orthodontics, School of Dental Medicine, University of \\ Belgrade, Belgrade, Serbia
}

Edited by: Aleksandar llie Citation: Milinkovic I, Mijallovic I, Markovic A, Janjic B, Nikolic N, Milasin J, Mich Adjunctive Application of Systemic Antibiotics in and Microbiological Findings. Open Access Maced J Med and Microbiological Findings. Open Access Maced J Med
Sci. 2021 Sep 01; 9 (D): 149-154 https://doi.org/10.3889/oamims.2021.685 Keywords: Periodontal disease; Aggressive periodontitis Non-surgical periodontal treatment; Antibiotic *Correspondence: Bojan Janjic, Department of Ora urgery, School of Dental Medicine, University of Belgrade, Belgrade, Serbia. bojanjanjic75@gmail.com Revised: 03-Aug-2021 Accepted: 22-Aug-2021

Copyright: @ 2021 lva Milinkovic, Iva Mijailovic, Aleksa Markovic, Bojan Janjic, Nadja Nikolic, Jelena Milasin, Biljana Milicic, Zoran Aleksic, Dina Vasovic Funding: This study was supported by Grant No. 451-039/2021-14/200129 of the Ministry of Education, Science and Technological Development of Republic of Serbia Competing Interest: The authors have declared that no competing interest exists Open Access: This is an openaccoss article distributed (CC BY-NC 4.0)

\begin{abstract}
BACKGROUND: Aggressive periodontitis (AgP) is associated with an extensive and rapid destruction of periodontal tissues. Unpredictable treatment outcomes of the disease are consequences of various cross-linked factors. Antimicrobial adjunctive treatment is routinely used as a part of non-surgical periodontal treatment (NSPT) of AgP.

AIM: Therefore, the aim of this study was to compare the effects of active periodontal treatment (APT) combined with systemic antibiotics with mechanical debridement alone, in patients with generalized AgP (GAgP).

METHODS: Two groups, consisting of 10 participants each, were randomly formed. Both groups were clinically and microbiologically tested and monitored for 3 months. Test group received APT with antimicrobial supplementation (amoxicillin and metronidazole [AMX-MET]). Patients from the control group were treated by APT only. Clinical and microbiological parameters were recorded at baseline and 3 months following the NSPT. Clinical measurements involved probing depth, clinical attachment level, bleeding on probing, and plaque index. Samples of subgingival crevicular fluid were analyzed by qualitative polymerase chain reaction.
\end{abstract}

RESULTS: Significant improvement of all clinical parameters was observed 3 months following the NSPT $(p<0.05)$ but significant difference between groups was not found $(p>0.05)$. Periodontal pathogens' detection between baseline and 3 months follow-up was also not statistically significant in both examined groups $(p>0.05)$

CONCLUSION: Similarity of results obtained in both treatment groups underlined the key role of APT in the treatment of AgP. The AMX-MET supplementation did not improve clinical and microbiological outcomes, when compared to APT alone. Longer follow-up period, with larger sample, could provide a more comprehensive insight into this issue.

\section{Introduction}

Aggressive periodontitis (AgP) is a form of periodontal disease which is associated with extensive and rapid periodontal destruction usually observed in systemically healthy population of younger age [1], [2]. The disease can be manifested in a generalized or a localized form. In a generalized form of AgP (GAgP), most of the permanent teeth (more than $30 \%$ of the existing dentition) are involved with a progressive periodontal tissue loss. The localized form mainly affects the permanent first molars and incisors. Regardless of the entity of AgP, the destructive process ultimately leads to tooth loss [2], [3].

Local accessory factors, such as dental plaque or calculus, which are crucial for chronic periodontitis development, play a minor role in the pathogenetic mechanism present in AgP [1], [4]. It is more likely that systemic factors, such as modified neutrophils' chemotaxis and phagocytosis, or monocytes' disorders, actually contribute to the severity of the disease [5]. Along with altered immune response, genetic aspects are highly important in patients with AgP, since there is a proven familiar aggregation. Polymorphisms in a number of genes (a gene for enzyme prostaglandinendoperoxide synthase-2, a gene for interleukin 10 , a gene that encodes defensin beta 1, etc.) are also considered as risk factors for AgP [5]. All of these factors make periodontal tissues prone to adverse effects of periodontal pathogens (PPs). PPs are grouped into five complexes based on their specific virulence factors [6]. The microorganisms found in AgP patients are Porphyromonas gingivalis (P.g.), Prevotella intermedia (P.i.), Tannerella forsythia (T.f.), and Treponema denticola (T.d.), and they belong to red and orange complexes. In the AgP, the high-risk PP is Aggregatibacter actinomycetemcomitans (A.a.), which is considered to be the main trigger of the destructive 
processes during the disease, due to its potent virulence factors [1], [5], [6].

The synergy between modified host response and the effect of PP compromises treatment outcomes. Therefore, a comprehensive treatment approach is necessary to arrest the disease and ensure stability of the obtained treatment results. In non-surgical periodontal treatment (NSPT), mechanical instrumentation, as a part of active periodontal treatment (APT), has an irreplaceable role [7], [8]. It has been demonstrated that APT combined with antibiotics provides significant improvements in the NSPT of AgP [9], [10], [11], [12].

However, the results obtained from the studiesare still inconclusive. Since different antibiotics have provided distinctive outcomes in $\mathrm{AgP}$ treatment, the disagreements mainly occur regarding the type of antibiotics that should be used as a supplementation to APT [9], [10], [11], [12], [13], [14], [15], [16], [17], [18], [19]. The use of amoxicillin (AMX) and metronidazole (MET) together (AMX-MET) is considered to be the most efficient, since the PPs of red and orange complexes, as well as A.a. are sensitive to both antibiotics [20], [21].

Based on the above mentioned, the aim of the present study was to compare clinical and microbiological effects between APT alone against APT combined with systemic antibiotics in patients with GAgP. The null hypothesis was that there would be no statistically significant differences in clinical and microbiological parameters over the 3 months observation period between the groups.

\section{Methods}

\section{Participants}

This study was a randomized controlled clinical trial. It was performed at the Department of Periodontology, School of Dental Medicine, University of Belgrade. The research protocol was approved by the Ethical Board of the University of Belgrade. All patients included in the study have read and signed an informed consent form before entering the study.

The subjects were included in the trial between September 2015 and June 2016, if they met the following inclusion criteria:

\section{- $\quad$ A diagnosis of GAgP [22]}

- $\quad$ Presence of at least 20 teeth

- $\quad$ Presence of at least one site with probing depth (PD) and clinical attachment level (CAL) values higher than $5 \mathrm{~mm}$ in incisors and first molars, and a minimum of six other teeth.

Patients allergic to penicillin, as well as those with systemic diseases known to contribute to treatment result were excluded from the study. Subjects were pregnant and lactating, so as the patients with a history of APT or antimicrobial use within 6 months prior the inclusion were defined as not being eligible for the study.

\section{Clinical evaluation}

Twenty patients were randomly assigned divided into two groups of 10 patients each using randomization envelopes.

The test group was treated by APT with antimicrobial supplementation of AMX-MET. Patients from the control group were treated by APT only. Clinical examinations and periodontal recordings were performed at baseline and 3 months following the NSPT by the same calibrated examiner (Figures 1 and 2). Treatment procedures were conducted during a 7-day period by the experienced periodontist.

The clinical parameters registered at baseline were the following: $P D, C A L$, bleeding on probing $(\mathrm{BOP})$, and plaque index $(\mathrm{PI})$. Periodontal probe (UNC-15, Hu-Friedy, Chicago, IL) was used to record the above-mentioned parameters. In the same session, supragingival deposits were removed (by both ultrasonic debridement and manual instrumentation). During the next 6 days, the participants received scaling and root planning under local anesthesia in two treatment sessions, using periodontal curettes. In the first session, the test group started antimicrobial supplementation that included $\mathrm{AMX}$ in dosage of $500 \mathrm{mg}$ and MET in dosage of $400 \mathrm{mg}, 3$ times per day for 7 days. All subjects were followed up monthly for oral hygiene evaluation and remotivation.

\section{Microbial assessment}

Subgingival crevicular fluid sampling of two periodontal pockets with a minimum PD of $5 \mathrm{~mm}$ was performed at baseline and 3 months following the NSPT. After isolating the area with cotton pellets, two standardized No. 30 sterile paper points (DiaDent Group International, Cheongju-si, Chungcheongbuk-do, Korea) were inserted in each periodontal defect for $30 \mathrm{~s}$. Samples were placed in Eppendorf tubes and kept at the temperature of $-20^{\circ} \mathrm{C}$.

Microbiological analysis was performed at the Institute of Human Genetics, School of Dental Medicine, University of Belgrade. To detect PP, DNA extraction and the polymerase chain reaction (PCR) were carried out by previously described and reported methods [18], [23]. After DNA extraction using Tris- $\mathrm{HCl}$ and sodium hydroxide, PCR mix was prepared for each of the examined PP separately (A.a., P.g., P.i., T.f., and T.d.). Following the DNA amplification, electrophoresis was performed. Ultimately, agarose gels were colored by ethidium bromide and PCR products were visualized under the ultraviolet light. 

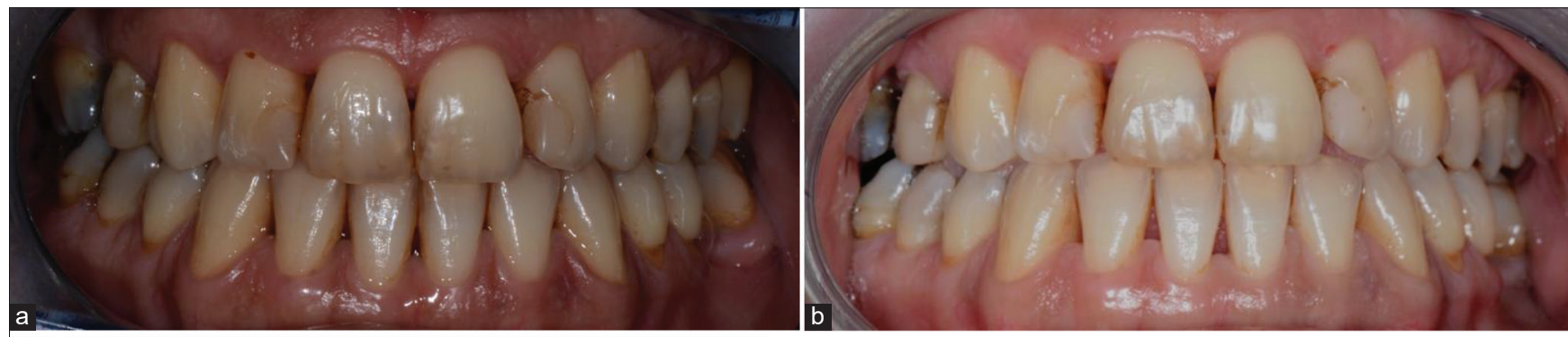

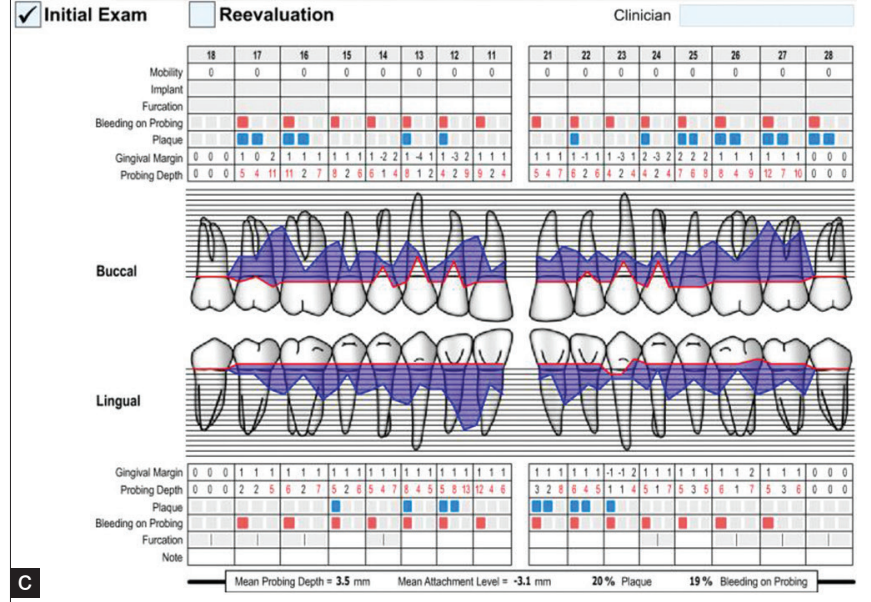

$\square$ Initial Exam $\checkmark$ Reevaluation

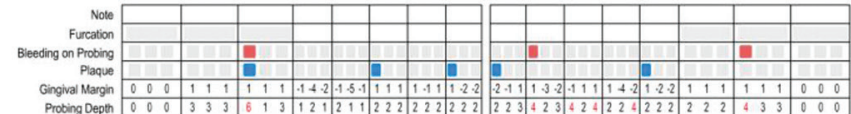

Lingu
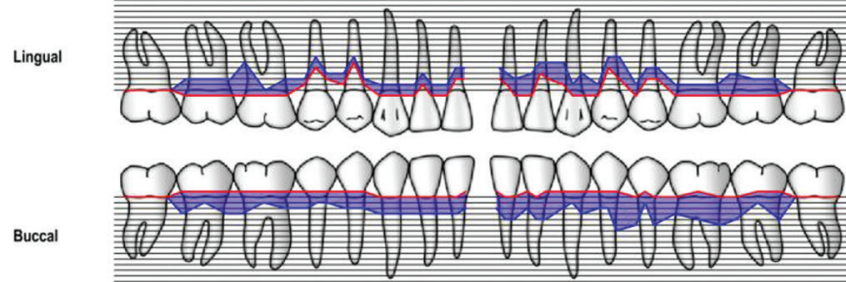

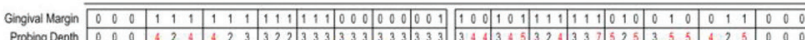

Plaque

Furcation
Implant
Mociiny

d

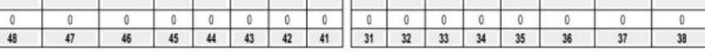

Clinician

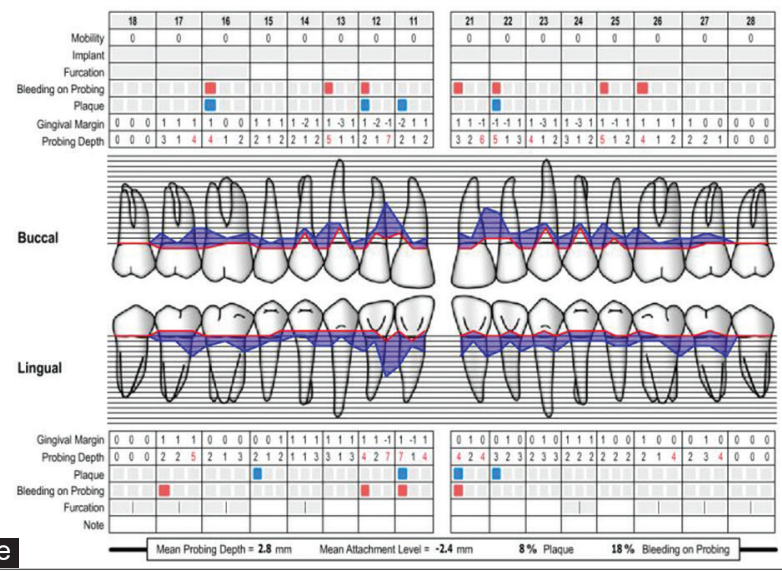

Figures 1: Clinical images and periodontal charts of a patient from the test group (APT + antibiotics). (a) Clinical situation at baseline. (b) Clinical view 3 months following the non-surgical periodontal treatment. (c) Periodontal chart with clinical parameters - upper jaw at baseline. (d) Periodontal chart with clinical parameters - lower jaw at baseline. (e) Periodontal chart with clinical parameters - upper jaw at 3 months follow-up

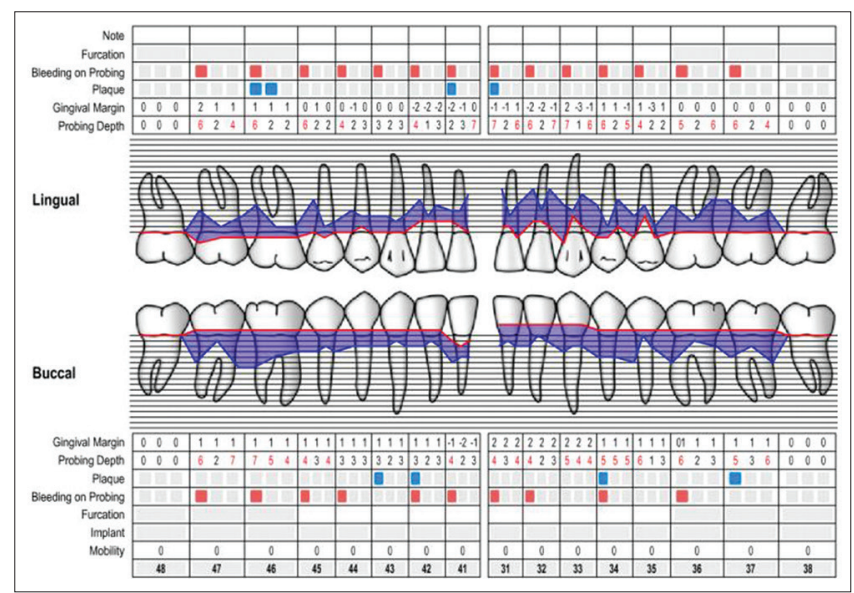

Figure 2: Periodontal chart with clinical parameters - lower jaw at 3 months follow-up

\section{Statistical analysis}

$p<0.05$ was required to reject the null hypothesis. Descriptive data for both groups were expressed as mean \pm SD for continuous measures or as a percentage of the group for discrete measures. Numeric data were tested for normal distribution using the Kolmogorov-Smirnov test. If the data were normally distributed, independent sample t-test and paired sample $\mathrm{t}$-test were used to assess differences in response, between and within the group. Non-parametric data were analyzed using the Mann-Whitney U-test and Wilcoxon test. Categorical data were analyzed by means of McNemar and Fisher's exact tests. Statistical analyses were performed using SPSS software version 26.0 (Chicago, IL, USA). 


\section{Results}

All participants included in the study were available for the follow-up, 3 months after the NSPT.

\section{Clinical findings}

Demographic characteristics of 20 patients included in the study are presented in Table 1. There were no significant differences among groups for any of the variables. No statistically significant difference was found between groups in terms of the following clinical parameters at baseline: PD, CAL, BOP, and PI. No statistically significant difference between groups was found 3 months following the treatment, neither.

Table 1: Patient characteristics

\begin{tabular}{|c|c|c|c|}
\hline Parameters & $\begin{array}{l}\text { Test group (APT } \\
+ \text { antibiotics) }\end{array}$ & Control group (APT) & $\mathrm{p}$-value \\
\hline Age (years), mean (SD) & $35.20(5.75)$ & $41.40(8.98)$ & ${ }^{a} p=0.083$ \\
\hline Gender, female/male (\%) & $6(60) / 4(40)$ & $6(60) / 4(40)$ & ${ }^{b} p=0.999$ \\
\hline Smokers (\%) & $7(70) / 3(30)$ & $5(50) / 5(50)$ & ${ }^{b} p=0.650$ \\
\hline Number of teeth (Med [IQR]) & $26.50(2.25)$ & $27.00(3.0)$ & ${ }^{c} p=0.083$ \\
\hline
\end{tabular}

Within each group, significant improvement in all the clinical parameters has been observed after the treatment (Table 2).

Table 2: Clinical parameters

\begin{tabular}{|c|c|c|c|}
\hline Parameters & $\begin{array}{l}\text { Test group (APT } \\
+ \text { antibiotics) }\end{array}$ & $\begin{array}{l}\text { Control } \\
\text { group (APT) }\end{array}$ & $\begin{array}{l}\text { ap-value } \\
\text { (between group) }\end{array}$ \\
\hline \multicolumn{4}{|l|}{ PD (mm); mean (SD) } \\
\hline Baseline & $3.75(0.65)$ & $4.23(0.98)$ & ${ }^{a} p=0.216$ \\
\hline 3 months & $2.33(0.82)$ & $2.79(0.71)$ & $a_{p}=0.196$ \\
\hline${ }^{\mathrm{b}} \mathrm{p}$-value (within group) & $p=0.001^{*}$ & $p=0.001^{*}$ & \\
\hline \multicolumn{4}{|l|}{$\mathrm{CAL}(\mathrm{mm}) ;$ mean (SD) } \\
\hline Baseline & $3.99(1.09)$ & $4.30(1.67)$ & ${ }^{a} p=0.629$ \\
\hline 3 months & $2.74(1.32)$ & $3.23(1.31)$ & $a_{p}=0.417$ \\
\hline${ }^{\mathrm{b}} \mathrm{p}$-value (within group) & ${ }^{b} p=0.012^{*}$ & $p=0.030^{*}$ & \\
\hline \multicolumn{4}{|l|}{$\mathrm{BOP}(\mathrm{mm}) ; \mathrm{Med}(\mathrm{IQR})$} \\
\hline Baseline & $0.95(0.4)$ & $0.20(0.70)$ & ${ }^{c} p=0.684$ \\
\hline 3 months & $0.85(0.5)$ & $0.30(0.30)$ & ${ }^{\circ} p=0.579$ \\
\hline${ }^{\mathrm{b}} \mathrm{p}$-value (within group) & $p=0.008^{*}$ & $\mathrm{~d} p=0.012^{*}$ & \\
\hline \multicolumn{4}{|l|}{ PI (mm); Med (IQR) } \\
\hline Baseline & $0.95(0.4)$ & $0.20(0.70)$ & ${ }^{c} p=0.796$ \\
\hline 3 months & $0.85(0.5)$ & $0.30(0.30)$ & ${ }^{\circ} p=0.853$ \\
\hline b-value (within group) & $p=0.008^{*}$ & $\mathrm{p}=0.005^{*}$ & \\
\hline
\end{tabular}

\section{Microbiological findings}

There was no statistical significance between groups at baseline as well as 3 months following the treatment in the prevalence of specific microbiological species (A.a., P.g., P.i., T.f., and T.d.) (Table 3). Intragroup analysis revealed that the highest decrease in microbial levels was found in the case of $A$.a. in the group that received antibiotic supplementation.

\section{Discussion}

The goal of the NSPT of AgP is to prevent further disease progression. In addition, it is desirable to get as much CAL gain as possible and to achieve PD, BOP, and PI reduction. Some forms of periodontal diseases, such as chronic periodontitis, especially in the initial phases, can be arrested by the NSPT. If so, proper oral hygiene and regular follow-ups are crucial for the maintenance of the treatment results [8]. Unfortunately, AgP responds less predictably to standard mechanical treatment than chronic periodontitis [7], [8].

Table 3: Microbiological findings before and after the treatment

\begin{tabular}{|c|c|c|c|}
\hline \multirow[t]{2}{*}{ Microbiological findings, $\mathrm{n}(\%)$} & \multicolumn{2}{|l|}{ Treatment } & \multirow{2}{*}{$\begin{array}{l}{ }^{\mathrm{a}} \mathrm{p} \text {-value } \\
\text { (between groups) }\end{array}$} \\
\hline & APT+antibiotics & APT & \\
\hline \multicolumn{4}{|l|}{ Porphyromonas gingivalis } \\
\hline \multicolumn{4}{|l|}{ yes/no } \\
\hline Baseline & $8(80 \%) / 2(20 \%)$ & $9(90 \%) / 1(10 \%)$ & ${ }^{a} p=0.999$ \\
\hline 3 months & $7(70 \%) / 3(30 \%)$ & $6(60 \%) / 4(40 \%)$ & $\mathrm{a}=0.999$ \\
\hline${ }^{b} \mathrm{p}$-value (within group) & $\mathrm{b}=0.999$ & $\mathrm{~b} p=0.250$ & \\
\hline \multicolumn{4}{|l|}{ Prevotella intermedia yes/no } \\
\hline Baseline & $7(70 \%) / 3(30 \%)$ & $8(80 \%) / 2(20 \%)$ & ${ }^{a} p=0.999$ \\
\hline 3 months & $5(50 \%) / 5(50 \%)$ & $6(60 \%) / 4(40 \%)$ & ${ }^{a} p=0.999$ \\
\hline bp-value (within group) & ${ }^{b} p=0.500$ & ${ }^{b} p=0.500$ & \\
\hline \multicolumn{4}{|l|}{ Aggregatibacter } \\
\hline \multicolumn{4}{|l|}{ actinomycetemcomitans yes/no } \\
\hline Baseline & $9(90 \%) / 1(10 \%)$ & $7(70 \%) / 3(30 \%)$ & ${ }^{a} p=0.582$ \\
\hline 3 months & $5(50 \%) / 5(50 \%)$ & $5(50 \%) / 5(50 \%)$ & $a=0.999$ \\
\hline${ }^{\mathrm{b}} \mathrm{p}$-value (within group) & ${ }^{b} p=0.125$ & ${ }^{b} p=0.500$ & \\
\hline \multicolumn{4}{|l|}{ Treponema denticola yes/no } \\
\hline Baseline & $6(60 \%) / 4(40 \%)$ & $6(60 \%) / 4(40 \%)$ & ${ }^{a} p=0.625$ \\
\hline 3 months & $2(20 \%) / 8(80 \%)$ & $2(20 \%) / 8(80 \%)$ & $\mathrm{a}=0.999$ \\
\hline bp-value (within group) & ${ }^{b} p=0.125$ & ${ }^{b} p=0.125$ & \\
\hline \multicolumn{4}{|l|}{ Tannerella forsythia yes/no } \\
\hline Baseline & $10(100 \%) / 1(10 \%)$ & $9(90 \%) / 1(10 \%)$ & ${ }^{a} p=0.999$ \\
\hline 3 months & $7(70 \%) / 3(30 \%)$ & 7 (70\%)/3 (30\%) & ${ }^{a} p=0.999$ \\
\hline${ }^{b} p$-value (within group) & ${ }^{b} p=0.500$ & ${ }^{b} p=0.500$ & \\
\hline
\end{tabular}

The present study evaluated clinical and microbiological effects of AMX-MET supplementation in the NSPT of GAgP. Clinical parameters demonstrated significant improvements in both treatment groups 3 months after the NSPT, with no significant difference between the groups. The obtained results implicate the key role of the APT and mechanical instrumentation in the treatment of $\mathrm{GAgP}$ [7], [8]. Several studies [9], [10], [24] have shown favorable effects of the adjunctive use of AMX-MET. Casarin et al. [10] have reported significant $P D$ reduction in AMX-MET supplemented patients, 3 and 6 months after the treatment, when compared to the placebo group. Regarding CAL, no significant difference was found between groups. In a retrospective study conducted by Guerrera et al. [25], patients with the adjunctive use of AMX-MET combination have shown significant improvements in PD, CAL, BOP, and PI 2 months after the NSPT. The exception was CAL values in periodontal pockets with initial PD $\leq 3 \mathrm{~mm}$. Rodrigues et al. [26] reported that 6 months following the NSPT and AMX-MET supplementation, decrease of PD, BOP, and $\mathrm{PI}$ was statistically significant. However, CAL values showed no statistical significance. Clinical outcomes of the current research are in accordance with the results obtained from the mentioned studies, and benefits of the AMX-MET application in the NSPT have been reshown. Nevertheless, the present study underlined the great role of the APT in the NSPT of GAgP. Significantly decreased clinical parameters in both tested groups point out that proper mechanical instrumentation provides optimal conditions for the disease arrest and are still an unsurpassed factor in the treatment of GAgP. 
Regarding microbiological analysis, the AMX-MET association has not been able to significantly decrease the presence of PP 3 months following the NSPT. Both treatment groups showed similar findings. Studies [10], [16], [26], [27] have shown the relation between AMX-MET use and decreased levels of some PP after the NSPT. In a study by Heller et al. [27], DNA-DNA hybridization technique has demonstrated statistically significant decrease in levels of A.a., P.g., and T.f., 3 and 6 months following the treatment. Casarin et al. [10] have conducted real-time PCR analysis and found significant reduction of $A$.a. and P.g. levels in the AMX-MET group, 3 and 6 months after the NSPT. There was no difference when compared to the placebo group. Results obtained in the present study are limited, due to the PCR method that has been used, with no possibility to present the differences in levels of each PP before and 3 months after the NSPT. Actually, qualitative PCR provided answer to only one question: Whether there was a specific PP in the sample or not. Even highly decreased PP levels in PCR products were registered as a "detected PP," and the sample was considered positive to particular bacteria. Advanced methods, such as a real-time PCR, would give a precise insight in the $\mathrm{PP}$ amounts and indirectly in the accurate results of the applied treatment.

Trials related to the adjunctive AMX-MET use in $\mathrm{AgP}$ are often limited with a number of participants, since the low prevalence of the disease [10], [25], [26], [27], [28]. In this study, 20 patients were included. Alarger patients' sample would probably lead to a greater relevance or even a modification of the results, although the sample of 20 patients with AgP should not be underestimated.

Follow-up periods of above-mentioned trials usuallyvarydependingonthestudy[9],[10], [16], [25], [26], and in the majority of them, patients were monitored 3 and 6 months after the treatment [4], [10], [11]. In the present research, obtained outcomes could be considered as a short-term result, since the period of only 3 months after the NSPT was evaluated. Several studies [3] investigated the long-term impact of antibiotic supplementation on periodontal disease progression. To the best of our knowledge, there are no studies that compare the long-term effects of various treatment approaches of AgP. Recently, Miller et al. [29] have shown the long-term results of clinical response to APT supplemented by AMX-MET in patients with localized form of $\mathrm{AgP}$. PD, CAL, and BOP improvements have been registered up to 4 years. However, this study did not include comparison between different approaches in the NSPT nor the microbiological analysis. Thus, further studies with precisely defined methodology are needed to compare the long-term effects of different treatment approaches in the NSPT of AgP. Real-time $\mathrm{PCR}$ for the microbiological assessment, as well as longer follow-ups is necessary to obtain more precise results on this matter.

\section{Conclusion}

Clinical and microbiological effects of the two performed treatment methods were similar. The AMX-MET supplementation did not significantly improve the outcomes when compared to APT alone, which indicate an importance of rigorous APT in the NSPT of AgP.

\section{References}

1. Armitage GC, Cullinan MP, Seymour GJ. Comparative biology of chronic and aggressive periodontitis: Introduction. Periodontol 2000. 2010;53(1):7-11. https://doi. org/10.1111/j.1600-0757.2010.00359.x

PMid:20403101

2. Albandar JM. Aggressive periodontitis: Case definition and diagnostic criteria. Periodontol 2000. 2014;65(1):13-26. https:// doi.org/10.1111/prd.12014

PMid:24738584

3. Harks I, Koch R, Eickholz P, Hoffmann T, Kim TS, Kocher T, et al. Is progression of periodontitis relevantly influenced by systemic antibiotics? A clinical randomized trial. J Clin Periodontol. 2015;42(9):832-42. https://doi.org/10.1111/jcpe.12441

PMid:26250060

4. Aimetti M, Romano F, Guzzi N, Carnevale G. One-stage fullmouth disinfection as a therapeutic approach for generalized aggressive periodontitis. J Periodontol. 2011;82(6):845-53. https://doi.org/10.1902/jop.2010.100468 PMid:21091345

5. Van der Velden U. What exactly distinguishes aggressive from chronic periodontitis: Is it mainly a difference in the degree of bacterial invasiveness? Periodontol 2000. 2017;75(1):24-44. https://doi.org/10.1111/prd.12202

PMid:28758297

6. Socransky SS, Haffajee AD, Cugini MA, Smith C, Kent RL Jr Microbial complexes in subgingival plaque. J Clin Periodontol. 1998;25(2):135-44. https://doi.org/10.1111/j.1600-051x.1998. tb02419.x

PMid:9495612

7. Teughels W, Dhondt R, Dekeyser C, Qurynen M. Treatment of aggressive periodontitis. Periodontol 2000. 2014;65(1):107-33. https://doi.org/10.1111/prd.12020

PMid:24738589

8. Scharf S, Wohlfeil M, Siegelin Y, Schacher B, Dannewitz B Eickholz P. Clinical results after nonsurgical therapy in aggressive and chronic periodontitis. Clin Oral Investig. 2014;18(2):453-60. https://doi.org/10.1007/s00784-013-1013-4 PMid:3749245

9. Mestnik MJ, Feres M, Figueiredo LC, Duarte PM, Lira EA, Faveri M. Short-term benefits of the adjunctive use of metronidazole plus amoxicillin in the microbial profile and in the clinical parameters of subjects with generalized aggressive periodontitis. J Clin Periodontol. 2010;37(4):353-65. https://doi. org/10.1111/j.1600-051x.2010.01538.x

PMid:20447259

10. Casarin RC, Ribeiro ED, Sallum EA, Nociti FH Jr., Goncalves RB, Casati MZ. The combination of amoxicillin and metronidazole improves clinical and microbiologic results of one-stage, 
full-mouth, ultrasonic debridement in aggressive periodontitis treatment. J Periodontol. 2012;83(8):988-98. https://doi. org/10.1902/jop.2012.110513

\section{PMid:22288485}

11. Ardila CM, Martelo-Cadavid JF, Boderth-Acosta G, ArizaGarces AA, Guzman IC. Adjunctive moxifloxacin in the treatment of generalized aggressive periodontitis patients: Clinical and microbiological results of a randomized, tripleblind and placebo-controlled clinical trial. J Clin Perodontol. 2015;42(2):160-8. https://doi.org/10.1111/jcpe.12345 PMid:25469723

12. Teughels W, Feres M, Oud V, Martin C, Matesanz P, Herrera D. Adjunctive effect of systemic antimicrobials in periodontitis therapy: A systematic review and meta-analysis. J Clin Periodontol. 2020;47(22):257-81. https://doi.org/10.1111/ jcpe.13264

PMid:31994207

13. Borges I, Faveri M, Figueiredo LC, Duarte PM, RetamalValdes B, Montenegro SC, et al. Different antibiotic protocols in the treatment of severe chronic periodontitis: A 1-year randomized trial. J Clin Periodontol. 2017;44(8):822-32. https:// doi.org/10.1111/jcpe.12721

PMid:28303587

14. Emingil G, Han B, Ozdemir G, Tervahartiala T, Vural C, Atilla G, et al. Effect of azithromycin, as an adjunct to nonsurgical periodontal treatment, on microbiological parameters and gingival crevicular fluid biomarkers in generalized aggressive periodontitis. J Periodontal Res. 2012;47(6):729-39. https://doi. org/10.1111/j.1600-0765.2012.01488.x

PMid:22571226

15. Guerrero A, Griffiths GS, Nibali L, Suvan J, Moles DR, Laurell L, et al. Adjunctive benefits of systemic amoxicillin and metronidazole in non-surgical treatment of generalized aggressive periodontitis: A randomized placebo-controlled clinical trial. J Clin Periodontol. 2005;32(10):1096-107. https:// doi.org/10.1111/j.1600-051x.2005.00814.x

PMid: 16174275

16. Guerrero A, Nibali L, Lambertenghi R, Ready D, Suvan J, Griffiths JD, et al. Impact of baseline microbiological status on clinical outcomes in generalized aggressive periodontitis patients treated with or without adjunctive amoxicillin and metronidazole: An exploratory analysis from a randomized controlled clinical trial. J Clin Periodontol. 2014;41(11):1080-9. https://doi.org/10.1111/jcpe.12299

PMid:25139116

17. Khattri S, Nagraj SK, Arora A, Eachempati P, Kusum CK, Bhat KG, et al. Adjunctive systemic antimicrobials for the nonsurgical treatment of periodontitis. Cochrane Database Syst Rev. 2020;11:CD012568. https://doi.org/10.1002/14651858. cd012568.pub2 PMid:33197289

18. Haas AN, Silva-Boghossian CM, Colombo AP, Susin C, Albandar JM, Oppermann RV, et al. Adjunctive azithromycin in the treatment of aggressive periodontitis: Microbiological findings of a 12-month randomized clinical trial. J Dent. 2012;40(7):556-63. https://doi.org/10.1016/j.jdent.2012.03.004 PMid:22445846

19. Jentsch HF, BuchmannA, FriedrichA, EickS. Nonsurgical therapy of chronic periodontitis with adjunctive systemic azithromycin or amoxicillin/metronidazole.ClinOral Investig.2016;20(7):1765-73. https://doi.org/10.1007/s00784-015-1683-1

PMid:26685849

20. Araujo CF, Andere NM, Dos Santos NC, Mathias-Santamaria IF, Reis AA, de Oliveira RD, et al. Two different antibiotic protocols as adjuncts to one-stage full-mouth ultrasonic debridement to treat generalized aggressive periodontitis: A pilot randomized controlled clinical trial. J Periodontol. 2019;20(12):1431-40. https://doi.org/10.1002/jper.18-0399 PMid:31257591

21. Shaddox LM, Walker C. Microbial testing in periodontics: Value, limitationsandfuture directions. Periodontol 2000.2009;50:25-38. https://doi.org/10.1111/j.1600-0757.2008.00285.x PMid:19388951

22. Armitage GC. Development of a classification system for periodontal diseases and conditions. Ann Periodontol. 1999;4(1):1-6.

PMid: 10863370

23. Noordhoek GT, Kaan JA, Mulder S, Wilke H, Kolk AH. Routine application of the polymerase chain reaction for detection of Mycobacterium tuberculosis in clinical samples. J Clin Pathol. 1995;48(9):810-4. https://doi.org/10.1136/jcp.48.9.810 PMid:7490312

24. Aimetti M, Romano F, Guzzi N, Carnevale G. Full-mouth disinfection and systemic antimicrobial therapy in generalized aggressive periodontitis: A randomized, placebo-controlled trial. J Clin Periodontol. 2012;39(3):284-94. https://doi. org/10.1111/j.1600-051x.2011.01795.x

PMid:22220822

25. Guerrero A, Echeverria JJ, Tonetti MS. Incomplete adherence to an adjunctive systemic antibiotic regimen decreases clinical outcomes in generalized aggressive periodontitis patients: A pilot retrospective study. J Clin Periodontol. 2007;34(10):897-902. https://doi.org/10.1111/j.1600-051x.2007.01130.x

\section{PMid: 17711478}

26. Rodrigues AS, Lourencao DS, Neto LG, Pannuti CM, Hirata RD, Hirata $\mathrm{MH}$, et al. Clinical and microbiologic evaluation, by realtime polymerase chain reaction, of non-surgical treatment of aggressive periodontitis associated with amoxicillin and metronidazole. J Periodontol. 2012;83(6):744-52. https://doi. org/10.1902/jop.2011.110333

PMid:22060046

27. Heller D, Varrela VM, Silva-Senem MX, Torres MC, FeresFilho EJ, Colombo AP. Impact of systemic antimicrobials combined with anti-infective mechanical debridement on the microbiota of generalized aggressive periodontitis: A 6-month RCT. J Clin Periodontol. 2011;38(4):355-64. https://doi. org/10.1111/j.1600-051x.2011.01707.x

PMid:21303403

28. Sjödin B, Matsson L, Unell L, Egelberg J. Marginal bone loss in the primary dentition of patients with juvenile periodontitis. J Clin Periodontol. 1993;20(1):32-6. https://doi.org/10.1111/j.1600051x.1993.tb01756.x

PMid:8421113

29. Miller KA, Branco-de-Almeida RS, Wolf S, Hovencamp N, Treloar $\mathrm{T}$, Harrison $\mathrm{P}$, et al. Long-term clinical response to treatment and maintenance of localized aggressive periodontitis: A cohort study. J Clin Periodontol. 2017;44(2):158-68. https:// doi.org/10.1111/jcpe. 12640

PMid:27767222 